\title{
Bioactive Sphingolipids as Biomarkers Predictive of Disease Severity and Treatment Response in Cancer: Current Status and Translational Challenges
}

\author{
MIRELA SEDIĆ, PETRA GRBČIĆ and SANDRA KRALJEVIĆ PAVELIĆ \\ Center for High Throughput Technologies, Department of Biotechnology, University of Rijeka, Rijeka, Croatia
}

\begin{abstract}
Recent translational studies in cancer have produced a wealth of evidence to support an association between sphingolipid metabolism and clinical outcomes, which underscores the clinical importance of sphingolipidrelated biomarkers in cancer diagnosis and prognosis. Importantly, circulating levels of bioactive sphingolipids were demonstrated to correlate with patient survival and treatment response in different tumour types, which could provide novel non-invasive cancer biomarkers. Here, we give a comprehensive overview of recent findings on bioactive sphingolipid species and protein regulators of their metabolism and signalling as novel potential biomarkers for risk assessment, prevention and prediction of treatment response in several types of solid cancers, including prostate, liver, pancreatic, breast and colon cancer, head and neck squamous cell carcinoma and gliomas. Finally, we critically discuss current issues in clinical translation of sphingolipid biomarkers and give our perspective on how these problems could be handled to facilitate implementation of sphingolipidbased diagnostics into clinical practice.
\end{abstract}

\section{An Introduction to Sphingolipid Structure and Metabolism}

Sphingolipids play an essential role as regulators of eukaryotic cell viability. Due to their amphiphilic properties, most sphingolipids are structural components of cell membranes. However, they can also be found in biological fluids such as in blood as constituents of circulating lipoprotein particles, or

Correspondence to: Dr Mirela Sedić, Radmile Matejčić 2, 51000 Rijeka, Croatia. Tel.: +385 51584574, Fax: +385 51584599, e-mail: msedic@biotech.uniri.hr

Key Words: Ceramide, sphingosine-1-phosphate, cancer, biomarker, diagnosis, treatment response, review. can be carried by other proteins (e.g. serum albumin). Sphingolipids are comprised of a long-chain sphingoid base (18 carbon amino-alcohol backbone) and a fatty acid or head group attached to the base. The most common sphingoid bases are sphingosine, dihydrosphingosine (sphinganine) and phytosphingosine (Figure 1) (1). Addition of fatty acids of different chain lengths or diverse head groups determines the biological functions of sphingolipids. Numerous variations in sphingoid bases, $N$-acyl-linked fatty acids and head groups contribute to the extreme structural diversity and complexity of this lipid class. Ceramide, a bioactive sphingolipid composed of sphingoid base and a fatty acid attached to the C2 position (Figure 1), serves as a precursor for the formation of all complex sphingolipids through addition of different head groups at $\mathrm{C} 1$ position of ceramide chain. For example, sphingomyelins, the most abundant sphingolipids, are formed by the addition of phosphocholine head group. Glycosphingolipids differ in the sugar residue attached to their base. Thus, glucosphingolipids contain glucose attached to the C1 hydroxyl position, whereas galactosphingolipids are formed by the addition of galactose to the base (Figure 1) (2).

Ceramides can be produced by either de novo synthesis or hydrolysis of complex sphingolipids (Figure 2). De novo synthesis of ceramide begins with the formation of 3ketodihydrosphingosine on the cytoplasmic side of the endoplasmic reticulum. Following 3-ketodihydrosphingosine reduction to dihydrosphingosine, the addition of different chain length fatty acids takes place to produce dihydroceramide. The latter reaction is called $N$-acylation and is catalysed by the family of enzymes known as ceramide synthases (CERS, formerly known as longevity assurance genes). There are six different CERS with distinct tissue expression, and each of them exhibits high specificity for the acyl CoA chain length for $N$-acylation, which determines the fatty acid composition of ceramides (Figure 3).

The formation of complex sphingolipids proceeds via three distinct routes of ceramide conversion to produce either 
glucosylceramide and sphingomyelin in the Golgi apparatus (3), or galactosylceramide in the endoplasmic reticulum (Figure 2) (4). While the formation of most abundant sphingolipids in the human body predominantly occurs in the trans-Golgi, synthesis of glucosylceramide takes place in the cis-Golgi where glucosylceramide synthase (GCS) catalyses the addition of UDP-glucose to a ceramide chain to form glucosylceramide (3).

Ceramide can also be used as a precursor for the formation of other sphingolipid species such as ceramide-1-phosphate (C1P) by ceramide kinase, mainly in the trans-Golgi but also in the plasma membrane. Ceramide can be hydrolysed to sphingosine and free fatty acid that leave the lysosome and enter salvage pathways serving as building blocks for other ceramide synthesis performed by CERS (5). Sphingosine can be further phosphorylated to sphingosine-1-phosphate (S1P) by the enzymes sphingosine kinase 1 and 2 (SPHK1 and -2), which can be degraded by either lipid phosphate phosphatases or by S1P lyase. The final degradation of ceramide is catalysed by ceramidases (acid, neutral and alkaline), a family of enzymes that have specific localization within the cell and therefore have specific affinity towards ceramides with particular fatty acid chain lengths.

\section{Simple Sphingolipids and Their Metabolic Enzymes in Cancer Formation and Progression}

Sphingolipid rheostat is defined as the balance between bioactive sphingolipids, in particular pro-apoptotic ceramide and sphingosine, and pro-proliferative ceramide-1-phosphate (C1P) and S1P. Maintaining this balance is important for normal functioning of the cell, and the enzymes responsible for ceramide production and its conversion to S1P have the main role in this process (Figure 3). In the development of cancer, overexpression of enzymes that steer ceramide metabolism towards the production of proliferative sphingolipid species is common. Thus, an up-regulation of ceramide kinase, ceramidases (in particular acid ceramidase) and SPHK1 and 2 have been reported in many cancer types, which opens novel avenues for therapeutic intervention in cancer.

SPHK1 has a demonstrated role in promoting tumour cell survival, proliferation, growth, differentiation and angiogenesis. Knockdown of SPHK1 leads to a decrease in the S1P level, increased amount of ceramide and inhibition of cancer cell survival, proliferation, invasion and migration of different cancer cells in vitro including colorectal (6), nonsmall cell lung (7), ovarian (8), acute myeloid leukaemia (9), prostate (10) and breast (11) cancer cells as well as glioblastoma (12) cells. Importantly, SPHK1 was recognized as a molecular regulator of interactions between tumour cells and the surrounding stroma via production of $\mathrm{S} 1 \mathrm{P}$, which is exported to the tumour microenvironment and signals through its cell-surface G-protein-coupled receptors, especially

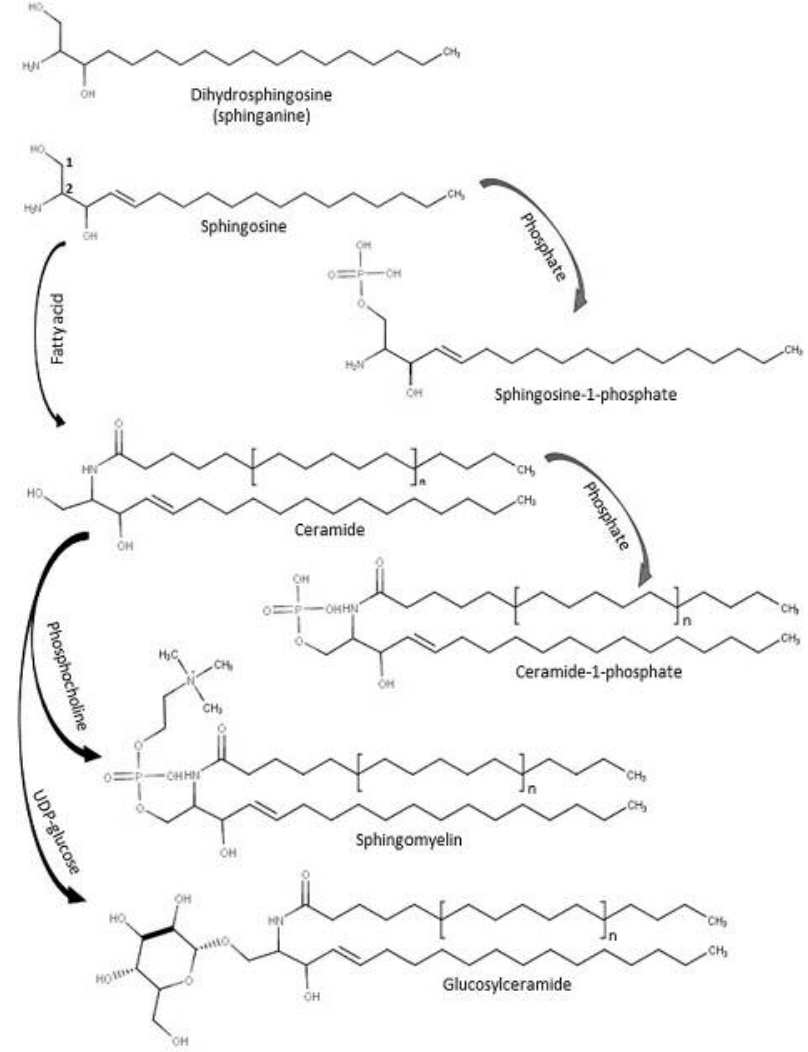

Figure 1. Structures of some simple and complex sphingolipids. The fatty acid moiety in the structures is indicated in brackets, where $n$ denotes variations in the fatty acid chain length.

sphingosine-1-phosphate receptors (S1PR1 to -3), (so-called 'inside-out' signalling) to promote cancer progression (13). Study in melanoma cells has shown that conditioned medium from SPHK1-expressing melanoma cells promotes differentiation of dermal fibroblasts into myofibroblasts, increases the production of matrix metalloproteinase- 2 and -9 involved in melanoma cell invasion, and increases SPHK1 expression and activity in fibroblasts. On the other hand, S1P released from SPHK1-overexpressing fibroblasts stimulates melanoma cell migration through binding to S1PR3 on the surface of melanoma cells. In vivo experiments in mice showed that co-injection of melanoma cells with wild-type skin fibroblasts markedly promoted tumour growth and development of metastasis in comparison with mice coinjected with $\mathrm{SPHKI}^{-/-}$fibroblasts (14). Altogether, these findings support the role of SPHK1 as a regulator of the cross-talk between dermal fibroblasts and melanoma cells, which is deemed critical for metastatic spread.

Although some studies have demonstrated the ability of SPHK2 to promote tumour progression, others have shown that knockdown or pharmacological inhibition of SPHK2 


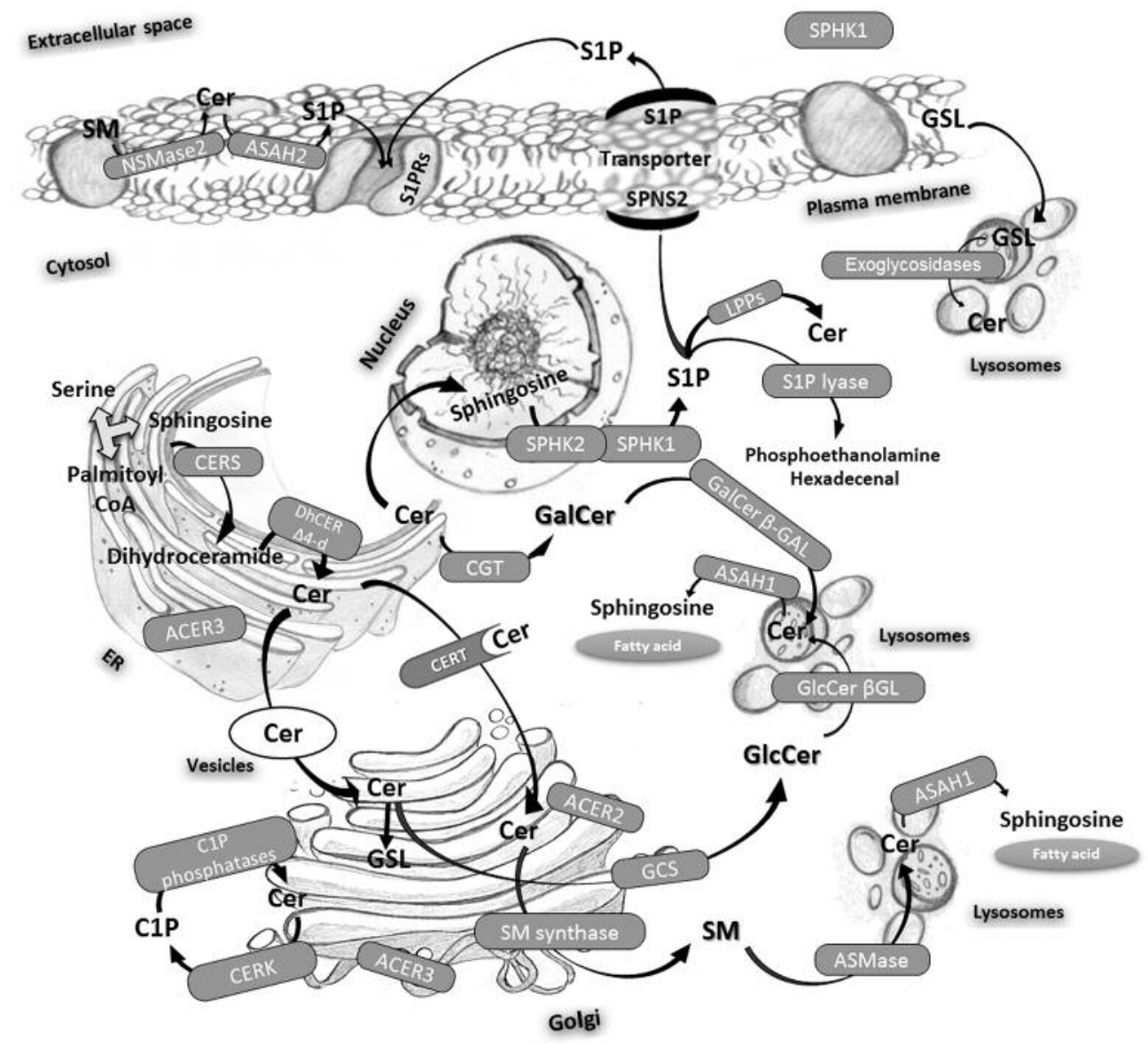

Figure 2. An overview of sphingolipid metabolic pathways. Cer: Ceramide; CERS: ceramide synthase; DhCER $44-d$ : dihydroceramide $44-$ desaturase; ACER: alkaline ceramidase; ASAH1: acid ceramidase; ASAH2: neutral ceramidase; CERK: ceramide kinase; SM: sphingomyelin; ASMase: acid sphingomyelinase; NSMase: neutral sphingomyelinase; GSL: glycosphingolipids; CGT: ceramide galactosyltransferase; GCS: glucosylceramide synthase; GalCer: galactosylceramide; GlcCer: glucosylceramide; C1P: ceramide-1-phosphate; S1P: sphingosine-1-phosphate; SIPRs: sphingosine-1-phosphate receptors; SPHK: sphingosine kinase; LPPs: lipoproteins; CERT: ceramide transport protein; GalCer $\beta$-GAL: galactosylceramide beta galactosidase; GlcCer $\beta G L$ : glucosylceramide beta glucosidase; SPNS2: protein spinster homolog 2.

reduces proliferation, inhibits growth, induces apoptosis and enhances sensitivity to anticancer drugs in different cancer types, including non-small cell lung (15), colorectal (16), bladder (17), prostate (18), ovarian (19) and hepatocellular (20) carcinoma. Moreover, depletion of SPHK2 expression has more potent antiproliferative, anti-migratory and antiinvasive effects in cancer cells than suppression of SPHK1 (21). Interestingly, the biological function of SPHK2 in cancer cells seems to be determined by its cellular expression level. Thus, high-level SPHK2 overexpression reduces cell proliferation and survival, while low-level SPHK2 overexpression facilitates cell survival and proliferation, induces oncogenic signalling and neoplastic transformation in vitro, and drives tumour formation in vivo (22).

Endogenous ceramides have been shown to exert opposing roles in the regulation of cancer cell growth and survival depending on their fatty-acid chain length, which brings into focus the importance of CERS in cancer pathogenesis (Figure 3). Studies in head and neck squamous cell carcinoma (HNSCC) have indicated that $\mathrm{C} 16$ ceramide produced by CERS6 promotes tumour proliferation, whereas CERS1generated C18 ceramide inhibits tumour growth (23). Similarly, an overexpression of CERS4 and CERS6 in human breast and colon cancer cells induced production of short-chain ceramides (C16:0, C18:0 and C20:0 ceramides), attenuated cell proliferation and promoted apoptosis, whereas up-regulation of CERS2 facilitated cell proliferation (24). Furthermore, coexpression of CERS with CERS4 and CERS6 in colon cancer cells reversed the suppression of cell proliferation and induction of apoptosis driven by long-chain ceramides (25). These and similar studies come the conclusion that a balance between very long- and long-chain ceramides govern cell 


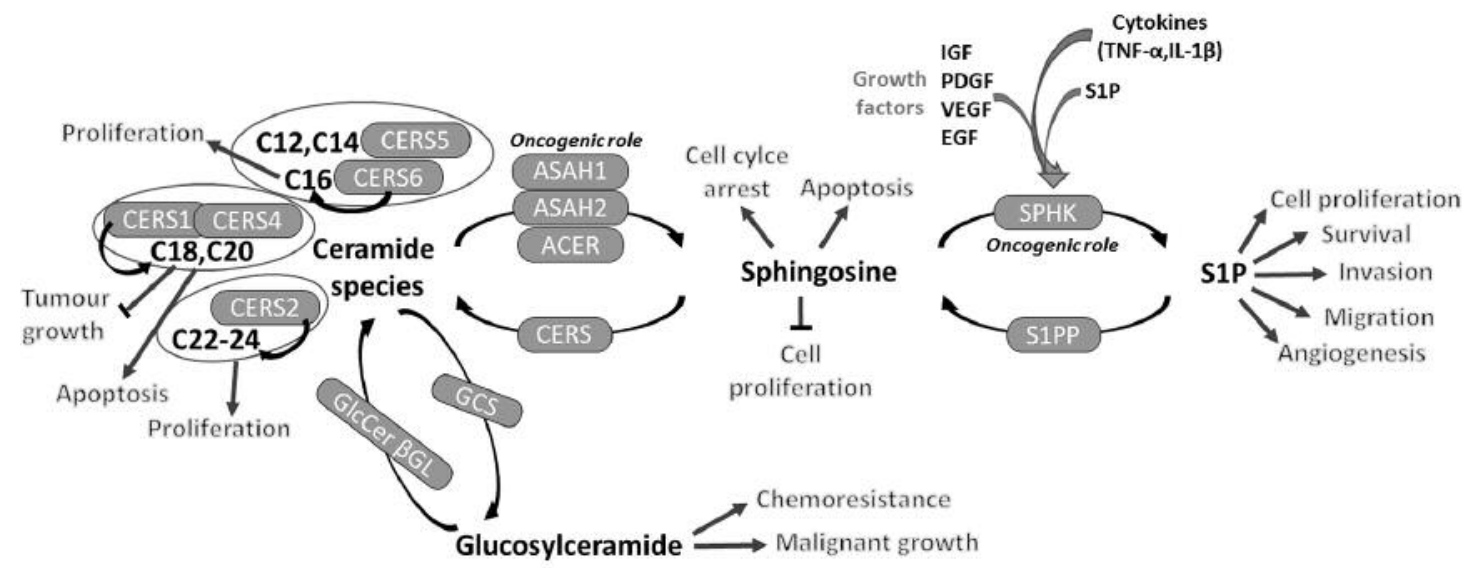

Figure 3. Roles of simple sphingolipids and their metabolic regulators in cancer cell behaviour and fate. SPHK: Sphingosine kinase; S1P: sphingosine-1-phosphate; SIPP: sphingosine-1-phosphate phosphatase; IGF: insulin-like growth factor; VEGF: vascular endothelial growth factor; EGF: epidermal growth factor; PDGF: platelet-derived growth factor; TNF- $\alpha$ : tumor necrosis factor- $\alpha$; IL-1 $\beta$ : interleukin 1 $\beta$; ASAH1: acid ceramidase; ASAH2: neutral ceramidase; ACER: alkaline ceramidase; CERS: ceramide synthase; GlcCer: glucosylceramide; GlcCer $\beta G L$ : glucosylceramide beta glucosidase.

behaviour and that dysregulation of the levels of distinct ceramide species contributes to tumorigenesis.

Aberrant regulation of ceramide metabolic enzymes is associated with tumorigenesis. For example, accumulation of acid ceramidase (ASAH1) was detected in different tumours, which suggests pro-proliferative and pro-survival role of this enzyme. Thus, targeting ASAH1 in prostate (26), hepatocellular (27), HNSCC (28), breast (29) and colorectal (30) carcinoma, melanoma cells (31), and leukaemia (32) is considered a promising strategy in fighting these malignancies.

Ceramide glycosylation catalysed by the enzyme GCS to produce glucosylceramide is a rate-limiting step in the biosynthesis of glycosphingolipids. The balance between ceramide and glucosylceramide or some other glycosphingolipids controls cellular behaviour and growth; GCS tips this balance in favour of the production of metabolites that promote malignant growth. Continuous ceramide glycosylation resulting from GCS overexpression drives cancer progression via regulation of the expression of genes associated with tumour metastasis, maintaining the stemness of cancer stem cells and acquisition of a drug-resistant phenotype (33). Indeed, excessive GCS was recognised as a cause of acquired drug resistance in different cancer cells including breast, ovarian, colonic and cervical cancer, leukaemia, and glioblastoma (34). Genetic or pharmacological inhibition of GCS increases the sensitivity of drug-resistant cancer cells including head and neck cancer (34), non-small cell lung cancer and malignant pleural mesothelioma (35), pancreatic cancer (36), and hepatocellular carcinoma (37) to different anticancer drugs in vitro and in vivo, which clearly indicates that targeting of GCS might be an efficient strategy to counter drug resistance in cancer.

\section{Sphingolipid Biomarkers in Cancer Prognosis and Stratification}

Prostate cancer. Prostate cancer $(\mathrm{PCa})$ is the second most common cancer in men worldwide. Currently, screening for $\mathrm{PCa}$ is based on measuring the blood level of prostatespecific antigen (PSA), but this approach suffers a lack of sensitivity and specificity. There is a wealth of evidence to support the role of S1P and SPHK1 as potential biomarkers for PCa diagnosis and prognosis $(38,39)$. Thus, it has been demonstrated that circulating levels of S1P decrease during early PCa progression due to down-regulation of erythrocyte SPHK1 activity, and were correlated with the clinical stage and grade. In addition, the finding that plasma S1P significantly correlates with the mortality of patients with PCa puts forward the idea of using circulating S1P as a predictive biomarker for PCa outcome (38). Further supporting a role of SPHK1 in prostate cancer-risk assessment, the enzymatic activity of SPHK1 was reported to be significantly increased in fresh tissues from patients with $\mathrm{PCa}$ in comparison with their non-tumorous counterparts, and to correlate with adverse clinical features (39). The finding that SPHK1 activity was correlated with odds ratios for treatment failure brought further evidence that SPHK1 holds the potential to be a clinical indicator of treatment efficacy in PCa.

Another enzyme of sphingolipid metabolism that has garnered attention as a novel potential PCa biomarker is ASAH1, whose increased expression at the gene level was detected in primary prostate tumour tissues when compared with matched normal tissues (40). The same study also 
showed that an upsurge in $A S A H 1$ gene expression was more common in grade 7 than grade 6 prostate tumours. Similar results were obtained at the protein level as well, showing that high histological grade prostate tumour samples have increased expression of ASAH1 when compared to patientmatched normal tissues (41). The correlation between ASAH1 expression and $\mathrm{PCa}$ progression was also corroborated by Camacho et al. (42), who carried out immunohistochemical analysis of primary PCa samples and found that higher levels of ASAH1 were associated with more advanced stages of PCa. All these studies clearly indicate that ASAH1 expression is linked to PCa severity, which may have further implications for the development of risk stratification strategies for patients with $\mathrm{PCa}$.

ASAH1 expression may also indicate the efficacy of treatment approach for $\mathrm{PCa}$, as demonstrated by Cheng et al. (43), who found significantly higher expression levels of ASAH1 in human PCa tissues after radiation therapy failure in comparison with therapy-naive $\mathrm{PCa}$, prostatic intraepithelial neoplasia, or benign prostate tissues. The same study also reported increased ASAH1 expression in PCa tissues after unsuccessful radiotherapy in comparison with patient-matched PCa tissues prior to radiation therapy. These findings suggest that ASAH1 expression might be a suitable biomarker for the evaluation of patient response to radiation therapy for $\mathrm{PCa}$ and the propensity for relapse. In addition, findings from preclinical studies showing enhanced response to radiotherapy and prevention of relapse in $\mathrm{PCa}$ induced by ASAH1 inhibition (43) encourage further investigation into targeting ASAH1 as adjuvant to radiotherapy in the clinical setting.

Liver cancer. Liver cancer has become the most common primary liver malignancy and the third leading cause of cancer-related deaths worldwide, and develops predominantly in patients with underlying chronic liver disease and cirrhosis (44). The clue that simple sphingolipids and their metabolic enzymes may have prognostic potential in liver cancer was provided by recent studies reporting that the expression of SPHK1 and SPHK2 is increased in tissues from patients with hepatocellular carcinoma (HCC) in comparison with matched adjacent non-cancerous tissues at the mRNA and protein levels, and was correlated with tumour size, stage, degree of tumour differentiation and microvascular invasion $(45,46)$. Furthermore, patients with HCC with high SPHK1 expression had shorter survival rates in comparison with those having low SPHK 1 expression, which suggests that up-regulation of SPHK1 might be an indicator for poor prognosis in HCC. A similar study reported that a higher level of $S P H K 2$ mRNA was a risk factor for intra- and extra-hepatic recurrence (46).

In spite of overexpression of both isoforms of sphingosine kinases in HCC tissues, the level of their phosphorylation product S1P was reported to be reduced in HCC tissues relative to non-tumorous tissues (46). This unexpected finding might be explained by increased degradation of S1P as deduced from elevated mRNA levels of S1P lyase in HCC tissues compared with non-HCC tissues. On the contrary, the levels of S1P and its precursor sphingosine in serum from patients with HCC were found to be elevated in comparison with patients with cirrhosis (47-49), which points to the diagnostic utility of long-chain sphingoid bases in HCC surveillance.

A similar distribution pattern was also observed for ceramides in HCC. Thus, the levels of different ceramide species were reported to be lower in HCC tissues in comparison with adjacent non-tumorous tissues (50). In contrast, a significant rise in the serum levels of different long-chain and very long-chain ceramides (C16-C24) was observed in patients with HCC compared to those with cirrhosis, among which $\mathrm{C} 16$ ceramide correlated with markers of hepatocellular injury (47). Similarly, Krautbauer et al. provided the evidence for the association between the ratio long-/very long-chain ceramides and the extent of liver injury (51). Importantly, both serum C16 ceramide and S1P had a high diagnostic accuracy in discriminating between patients with HCC and those with liver cirrhosis, and even outperformed the current clinical biomarker for $\mathrm{HCC}$, namely alpha-fetoprotein, in HCC diagnosis (47). A similar study also showed S1P to have good sensitivity and specificity in discriminating between patients with HCC and those affected by hepatitis C-associated cirrhosis (49). Collectively, all these findings highlight the potential of $\mathrm{C} 16$ ceramide and $\mathrm{S} 1 \mathrm{P}$ as novel diagnostic markers for detection of HCC in patients with liver diseases.

Pancreatic cancer. Pancreatic cancer remains the fourth cause of cancer-related deaths worldwide (52). Due to occurrence of specific clinical symptoms only when disease reaches the late stage, pancreatic cancer is characterised with a high mortality rate. The only clinically approved bloodbased biomarker for the management of pancreatic cancer, namely carbohydrate antigen 19-9, has limited sensitivity and specificity, and fails to accurately differentiate patients with pancreatic cancer from healthy individuals and from those diagnosed with some other non-pancreatic neoplastic condition or benign pancreatic disease (53).

Several previous studies lend support to the idea that ceramides and their metabolites are implicated in pathogenesis and that altered regulation of their metabolism is associated with a more aggressive phenotype in pancreatic cancer. Specifically, the levels of C16:0 and C24:1 ceramides are significantly higher in pancreatic tissues from patients with positive regional lymph node metastasis of pancreatic cancer than in patients without such metastases and patients with pancreatitis (54). Although no significant difference was observed in pancreatic tissue levels of S1P and dihydrosphingosine-1-phosphate, these two 
long-chain bases were found to be markedly increased in the plasma from patients with metastasis of pancreatic cancer compared to patients with non-metastatic pancreatic cancer and those with pancreatitis (54). Another study provided additional evidence that sphingoid bases may prove useful in diagnosis of pancreatic cancer. Thus, it has been found that D-sphingosine is significantly up-regulated in the serum of patients with pancreatic cancer in comparison with healthy controls (55). Importantly, the same study showed good sensitivity and specificity for sphingosine in differentiating between patients and controls. Further studies are warranted to explore the clinical utility of specific ceramide species and sphingoid bases as possible discriminatory biomarkers indicative of early onset of pancreatic cancer and to investigate whether their combination with carbohydrate antigen 19-9 holds potential for improving diagnosis.

Colon cancer. Colon cancer represents the third most common type of malignancy and the fourth major cause of cancer-associated deaths in the world (56), and poses great challenges in terms of timely detection and clinical management. Although genetic and epigenetic events underlying adenoma to carcinoma progression in colorectal cancer have been extensively studied, its detection, particularly in early stages, is hampered due to the heterogeneous nature of this disease and the absence of noninvasive clinical biomarkers with an adequate diagnostic performance that would be used as a stand-alone diagnostic tool (57). This is exactly the area where sphingolipids and the enzymes regulating sphingolipid metabolism may come into play since their roles in colon carcinogenesis have been propounded by numerous studies. Among these, SPHK1 stands out as a promising candidate biomarker since its expression was shown to be increased in colon cancer tissues compared to matched adjacent normal mucosa (58-60). SPHK1 expression in adenocarcinomas was found to be significantly up-regulated compared to both normal mucosa and adenomas (59), which implies that SPHK1 plays a central role in colon cancer progression. Importantly, SPHK1 might be considered a promising biomarker for detection and risk assessment of metastatic colorectal cancer because its expression in metastatic colon cancer tissues is markedly increased compared to colon cancer without metastasis (59). Similar studies also set a role for SPHK1 in malignant progression in colon cancer by demonstrating that overexpression of SPHK1 in colorectal cancer tissues significantly correlates with lymph node metastasis, liver metastasis, and advanced tumour stages $(61,62)$. The finding that SPHK1 is a significant independent predictor of mortality in patients with colon cancer (62) raises the possibility that SPHK1 expression might be of clinical interest for improving risk stratification for death from metastatic colorectal cancer in order to guide decisions about best intervention options for this group of patients. In addition to its prognostic significance, SPHK1 holds potential in predicting treatment efficacy in patients with colon cancer as demonstrated in a study by Rosa et al. (63), who found that high tumour tissue levels of SPHK1 significantly correlated with poor response to cetuximabbased therapy in patients with colorectal cancer with wildtype Kirsten rat sarcoma viral oncogene homolog $(K R A S)$.

Other evidence to support a predictive value of the SPHK/S1P axis in colorectal cancer was provided by Lin $e t$ al. (64). They investigated the expression and prognostic significance of S1PR1 at the protein level in patients with colorectal cancer and showed it to be significantly upregulated in lesions compared to adjacent non-tumorous tissues. A clinically relevant finding arising from this study was that increased intratumoural S1PR1 expression was associated with metachronous liver metastasis and poor overall survival, and was identified as an independent prognostic predictor for worse outcome in colorectal cancer. Similarly, increased expression of S1PR1 was found in tumour tissues from patients with colorectal cancer compared with normal tissues in another study (60). On the contrary, the same authors found that the expression of S1PR2 was markedly decreased at the gene and protein levels in tumour in comparison with normal tissues and demonstrated that pharmacological and genetic inhibition of S1PR2 facilitated the migration and invasion of colon cancer cells in vitro.

Aberrant regulation of the key regulatory nodes in sphingolipid metabolism creates an imbalance between proand anti-apoptotic sphingolipid species, which endows colon cancer cells with an invasive and metastatic phenotype. Distinct sphingolipid signatures could, thus, serve as an indicator for colorectal cancer progression stage. Indeed, a recent retrospective pilot study showed a significant increase in the serum levels of C16-, C18-, C18:1- and C24:1ceramides, as well as those of sphingosine, in patients with metastatic stage IV colorectal cancer in comparison with controls (65). Importantly, this study demonstrated that ceramides were significantly associated with stage IV CRC. Deregulation of ceramide metabolism was also observed in tumour tissues from patients with colorectal cancer (among which $2 \%, 45 \%, 42 \%$ and $11 \%$ had tumour stages I, II, III and IV, respectively), where significantly increased levels of C16:0, C24:0 and C24:1 ceramide were detected, whereas the levels of $\mathrm{C} 18$ and $\mathrm{C} 20$ ceramides were decreased in comparison with adjacent non-cancerous tissues (66). Among these, very long-chain ceramides seem to be associated with metastatic and aggressive behaviour of colorectal cancer, as up-regulation of C24:0 ceramide positively correlated with lymph node invasion, and a higher level of C24:1 was observed in metastatic tissues. Partial discrepancies between the levels of particular ceramide species measured in serum and tissue samples in the two independent studies described 
above could, at least to some extent, be explained by the fact that patients enrolled in these studies had different tumour stages of colorectal cancer, which again indicates that each step in the progression of colorectal cancer is associated with specific perturbations in sphingolipid metabolism. Other factors that might potentially contribute to observed differences include heterogeneity within tumours not reflected in the human plasma samples and difficulty in selecting and enrolling adequate controls (67). Observed alterations in ceramide content in colon cancer might be attributed to aberrant regulation of the ceramide metabolic pathway. Indeed, CERS1, $-2,-5$ and -6 were shown to be overexpressed in tissues from patients with colorectal cancer in comparison with patient-matched adjacent normal mucosa (66, 68, 69). Importantly, CERS5 correlated with poor patient survival and was an independent predictor of 5-year overall survival and disease recurrence in patients with colorectal cancer (69).

Besides their potential use in surveillance of colorectal cancer progression, ceramides may also prove useful in stratifying patients according to treatment response, which could facilitate the development of tailored approaches to increase the efficacy of treatment. The feasibility of this concept was demonstrated by Dubois et al. (70), who investigated the potential of plasma ceramide as a predictor of response to hypofractionated stereotactic body radiation therapy in combination with irinotecan chemotherapy in patients with metastases derived from primary colorectal carcinomas. Their study revealed a significant rise in the plasma levels of total ceramide and specific ceramide species including C16:0, C18:0, C20:0, C22:0, C22:1, C24:0, and C24:1 ceramide in objective responders compared with nonresponders early during treatment. Importantly, clustering analysis of patients according to plasma levels of total ceramide was able to clearly distinguish between responders and non-responders, which suggests that plasma ceramide levels might be considered predictors of response to stereotactic body radiation therapy combined with irinotecan in patients with colorectal cancer.

Head and neck squamous cell carcinoma. Squamous cell carcinoma makes up more than $90 \%$ of cancers of the head and neck and develops in the mucous membranes of the upper aerodigestive regions including oral cavity, oropharynx, nasal cavity and paranasal sinuses, nasopharynx, larynx and hypopharynx. HNSCC represents the seventh most frequent malignancy worldwide accounting for more than half a million new cases each year (71). In spite of improvements in surgery, chemotherapy and radiation, the 5 -year survival rate of patients with advanced and recurrent disease remains poor. One of the reasons for unsuccessful management of patients with HNSCC is the high genomic complexity and high mutation rate in comparison to other malignancies (72). Thus, identifying multiple molecular biomarkers for predicting clinical outcome and response to therapy in HNSCC patients could move the field forward.

A wealth of evidence supports the notion of dysregulated sphingolipid metabolism, in particular of ceramide, in HNSCC. Loss of ceramide is indicative of HNSCC progression since tissue ceramide progressively was found to diminish from normal laryngeal mucosa via laryngeal precancerous lesions to laryngeal squamous cell carcinoma (73, 74). Similarly, Young et al. reported that premalignant oral lesions and oral squamous cell carcinoma had lower ceramide levels in comparison with normal keratinocytes (75). The decrease in ceramide level observed in these studies can be attributed to either its breakdown or its metabolic conversion to more complex sphingolipids. Indeed, ceramide-degrading enzyme ASAH1 was found to be up-regulated at both the protein and mRNA levels in the majority of studied HNSCC tumour tissues compared with paired normal tissues $(28,41,76)$. Moreover, an increase in the levels of particular neutral glycosphingolipids, including glucosylceramide and galactosylceramide, was also detected in HNSCC tumour tissues compared to normal tissues (77), which substantiates that the observed reduction in ceramide pools may be partially ascribed to metabolic conversion to specific glycosphingolipid species that propel neoplastic growth and malignant transformation in HNSCC.

In contrast to these findings, another study reported that the total ceramide levels were higher in HNSCC tumour tissues than in their matched adjacent non-cancerous tissues (78). However, the analysis of individual ceramide species further revealed that only $\mathrm{C} 18$ ceramide (both $\mathrm{C} 18: 0$ and C18:1 ceramides) was selectively significantly reduced in the HNSCC tumour tissues when compared to their adjacent non-tumorous tissues $(78,79)$. Thus, alterations in the level of a specific ceramide rather than total ceramides might serve to estimate clinical rate of progression of disease in patients with HNSCC. Additional evidence to support the diagnostic importance of individual ceramide species, in particular of $\mathrm{C} 18$ ceramide, was provided by Karahatay et al. (79). They reported that lower levels of C18 ceramide in HNSCC tumour tissues $v s$. normal tissues were significantly correlated with higher incidences of lymphovascular invasion and nodal metastasis. Thus, a decline in tissue level of C18 ceramide should be taken into consideration as a potential indicator for the diagnosis of advanced HNSCC. Still, additional studies investigating the relationship between $\mathrm{C} 18$ ceramide levels and the overall survival of the patients with HNSCC are warranted to ascertain prognostic significance of $\mathrm{C} 18$ ceramide. Further effort to evaluate the potential clinical utility of $\mathrm{C} 18$ ceramide in the management of HNSCC was undertaken in a phase II clinical trial reported by Saddoughi et al. (80). In this clinical study, patients with recurrent or metastatic HNSCC showing non-responsiveness 
to first-line platinum-based therapy had been receiving gemcitabine and doxorubicin, and their serum levels of ceramides (C12 to C26 ceramides), C16-dihydro-ceramide, sphingosine, and S1P were measured every two treatment cycles ( 6 weeks). Among the measured sphingolipids, only serum $\mathrm{C} 18$ ceramide proved to be clinically relevant, as statistically significant differences were observed in the patterns of increase of $\mathrm{C} 18$ ceramide in patients with complete response, partial response and stable disease $v s$. patients with progressive disease after two treatment cycles (80). This finding strongly suggests that serum C18 ceramide represents a promising candidate biomarker of response to chemotherapy in patients with HNSCC.

There is ample evidence that enzymes regulating sphingolipid metabolism also hold great potential for diagnostic applications in HNSCC. In particular, attention has been focused on SPHK1, whose expression was shown to be up-regulated in HNSCC tumour tissues in comparison with matched normal tissues (81-85). Several lines of evidence demonstrate that increased expression levels of SPHK1 correlate with advanced tumour stage, locoregional recurrence and distant metastasis $(83,86)$. A study by Li et al. revealed that patients with nasopharyngeal carcinoma with high expression levels of SPHK1 had markedly shorter overall survival, and that SPHK1 was an independent prognostic indicator for nasopharyngeal carcinoma (83). The prognostic relevance of SPHK1 expression was also corroborated in oral squamous cell carcinoma in a study by Facchinetti et al. (82), who found that positive expression of SPHK1 was associated with a worse outcome.

Gliomas. Gliomas are tumours that arise from the glial cells. The most common type of glioma in adults and children are astrocytomas, which develop from astrocytes, brain cells that support neurones. Astrocytomas can be slow (low grade) or fast growing (high grade), or grades from I to IV. Among these, the most aggressive and malignant form of astrocytoma is glioblastoma multiforme, the highest grade glioma (grade IV) tumour. Glioblastoma is distinguished from lower-grade glioma by the presence of necrosis and angiogenesis, high mitotic index and rapid infiltration into adjacent healthy brain tissue, which represents a formidable hurdle to successful treatment, resulting in an average 5-year survival rate of less than $5 \%$ and a median survival time of 14.6 months (87).

A wealth of evidence supports the notion that identification of specific aberrations in the sphingolipid content and signalling might add new pieces to the puzzle of the complex pathophysiology of gliomas to improve diagnosis, prognosis and prediction of treatment response. Findings from different studies converge to indicate that deregulation of ceramide metabolism is associated with neoplastic transformation and malignant progression in human astrocytoma. It has been reported that ceramide levels are markedly lower in astrocytoma than in normal brain tissue, and that a significant decrease in the amount of ceramide was observed with a progressively increasing malignancy grade $(88,89)$. These observations clearly point to an inverse correlation between ceramide levels and the malignant potential of astrocytoma. Reduction in ceramide content detected in glioma tissues was mainly ascribed to depletion of $\mathrm{C} 18$ ceramide (C18:1 and C18:0 ceramide) (88). Importantly, ceramide levels were shown to be significantly associated with the survival of patients with glioma. The patients with glioma with the shortest survival time had the lowest ceramide level, which implies that ceramide levels might be a predictor of outcome (89).

A possible explanation for the low levels of ceramide especially in high-grade gliomas may reside in deregulation of the molecular mechanisms that control ceramide homeostasis, in particular ceramide breakdown. Indeed, the expression of ASAH1 was detected in adult and paediatric gliomas $(88,90)$. Moreover, increased expression of ASAH1 was associated with shorter progression-free survival and lower overall survival (91). This enzyme also plays an important role in radioresistance of glioblastoma $(90,92)$. Thus, Doan et al. demonstrated up-regulation of $A S A H 1$ in recurrent glioblastoma tissues from patients after radiotherapy compared to patient-matched glioblastoma tissues before radiation (92). Another molecular factor contributing to loss of ceramide in gliomas includes B-cell lymphoma 2 like 13 (BCL2L13), a CERS inhibitor which is up-regulated in glioblastoma (93). BCL2L13 binds to proapoptotic CERS2) and CERS6, leading to the inhibition of CERS2/6 complex activity. Thus, suppression of BCL2L13 might be an efficient strategy to restore cellular levels of ceramide in glioblastoma and improve clinical outcome in these patients.

Differential analysis of sphingolipid metabolites between human astrocytoma tissues and normal grey matter tissue also revealed an increase in the levels of S1P in glioblastoma tissues compared with normal grey matter. Importantly, the level of S1P rose with increasing glioma grade (88). Accumulation of $\mathrm{S} 1 \mathrm{P}$ in glioblastoma tissues may result either from its excessive production or from inhibition of its de-phosphorylation and cleavage. Indeed, several studies have reported that the expression of SPHK1 is higher in glioblastoma tumour tissues than in normal brain $(88,94-96)$. Furthermore, the expression of S1P phosphatase 2 (SGPP2) which dephosphorylates S1P to produce sphingosine, was found to be reduced in glioblastoma tumour tissues in comparison with normal grey matter. Importantly, increased tumour levels of S1P significantly correlated with increased SPHK1 and reduced SGPP2 expression levels (88).

SPHK1 was recognised as a potential prognostic indicator for patients with glioblastoma since its expression level correlates 
with worse outcome in these patients $(12,95)$. Thus, patients with glioblastoma with high levels of SPHK1 expression had a significantly shorter survival time in comparison with those with low levels of SPHK1 expression $(12,95)$. Results from different studies reinforce the role of SPHK1 as a critical regulator of malignant progression to high-grade gliomas $(94,95)$. It has been demonstrated that SPHK1 expression progressively increases from primary up to recurrent and to secondary glioblastoma tumour tissues in comparison with non-tumorous brain tissues (94). Similar studies demonstrated a significant correlation between the expression of SPHK1 and the histopathological staging of astrocytomas by showing that the degree of SPHK1 overexpression increases with progressively increasing grades of astrocytoma $(88,95)$. In light of these findings, analysis of SPHK1 expression may have further clinical implications in the stratification of patients according to glioma aggressiveness.

S1P can also be produced by SPHK2, although there seems to be an opposing regulation of SPHK1 and SPHK2 levels in human glioma. Unlike SPHK1, which is critically involved in late stages of glioma progression, SPHK2 seems to be important for early stages of glioma carcinogenesis. SPHK2 was detected in glioblastoma specimens, with highest levels observed in primary tumours compared to nontumorous brain tissues $(12,94)$. Similar results were obtained by Abuhusain et al., who found that SPHK2 expression was down-regulated in glioblastoma tissues relative to normal grey matter, and that lower glioma grade had higher SPHK2 expression levels (88).

S1P exerts its cellular effects through specific receptors, S1PRs, located on the plasma membrane to regulate glioblastoma cell proliferation, motility and invasiveness (97). Human glioblastoma tissues overexpress several receptors for S1P including S1PR1, S1PR2, S1PR3 and S1PR5 compared to normal non-cancerous brain tissue, and their expression gradually increases from primary to recurrent tumours and reaches a peak level in secondary glioblastoma tissues compared to normal brain tissue $(12,94$, 98). Bien-Möller et al. also found significantly increased expression levels of S1PR1, S1PR2 and S1PR3 in glioblastoma tissues in comparison with non-malignant brain, but unlike previous reports, they revealed a trend towards a decrease in the S1PR5 expression level in glioblastoma tissues. Moreover, these authors did not detect significant differences in the expression of S1PRs between patients with primary tumours and those with relapse (96).

Interestingly, Yoshida et al. also reported that human glioma expressed S1PR1, S1PR2, S1PR3 and S1PR5, but their findings partially stand in contrast to similar studies by showing a significant decline in the expression level of S1PR1 in glioblastoma tissues in comparison with normal brain tissues (99). These authors also showed that the expression levels of S1PR1 were significantly reduced with increasing histological tumour grade in human astrocytoma tissues $(99,100)$. Such variations in the expression levels of S1PRs in glioblastoma tumour tissues between different studies might be potentially associated with a marked heterogeneity of glioblastoma at the cellular, molecular, genetic, epigenetic and metabolic levels (101).

It has been suggested that the expression level of S1PR1 might be a prognostic factor for glioblastoma since low expression of S1PR1 significantly correlated with poor survival of patients with glioblastoma $(96,99,100)$. In contrast, the expression of S1PR2 and S1PR5 negatively correlated with the survival time of patients with glioblastoma. Thus, patients with glioblastoma with high expressions of S1PR2 and S1PR5 had a significantly shorter survival time in comparison with those with low expression of these receptors $(94,96)$. Inverse expression levels of S1PRs in relation to prognosis of patients with glioblastoma might be at least partially attributed to the propensity of individual receptor subtypes to regulate distinct aspects of glioma cell behaviour as well as to intricate nature of interactions between these receptors and other tumourpromoting factors $(96,102)$.

Breast cancer. Breast cancer is a heterogeneous disease with four intrinsic molecular subtypes having distinct clinical outcomes that differ in the expression of oestrogen receptor (ER), progesterone receptor (PR), and overexpression of human epidermal growth factor receptor 2 (HER2/neu). These subtypes are designated luminal A, luminal B, HER2 overexpressing, and basal-like breast cancer. Luminal A tumours represent those that are ER-/PR-positive and HER2 negative, whereas luminal B are ER-/PR-positive and HER2positive. Luminal B tumours are often of higher grade and have worse prognosis than the luminal A subtype (103).

Observations from different studies indicate that bioactive sphingolipids are markedly elevated in tumour tissues from patients with breast cancer in comparison with normal breast tissues. In particular, a significant increase in the levels of sphingoid bases including sphingosine, dihydrosphingosine, S1P and dihydro-S1P was detected in tumour tissues compared to patient-matched non-cancerous breast tissues (104). The same study found a correlation in the levels of S1P between the tumour and patient-matched normal breast tissues, suggesting that S1P mediates the interaction between tumour cells and the surrounding normal breast tissue. Elevated levels of sphingosine, dihydrosphingosine and S1P but not dihydroS1P were also found in interstitial fluid from human breast tumour tissue compared to that from normal breast tissue (105), which adds another layer of evidence to support the role of S1P signalling in the tumour microenvironment that could be important for breast cancer invasion and metastasis.

Additional data argue that S1P is critically involved in breast cancer metastatic progression, as markedly increased 
levels of S1P were found in the tumour tissues from patients with lymph node metastasis of breast cancer compared to those with negative nodes (106). Similarly, a marked rise in the serum level of S1P was documented in stage IIIA breast cancer with lymph node metastasis in comparison with age/ethnicity-matched healthy volunteers (107). Findings from these studies bear out the role of S1P levels as a potential biomarker of lymphatic metastasis in breast cancer.

S1P levels are also associated with specific molecular subtypes of breast cancer. In particular, elevated tumour tissue levels of S1P were found in luminal A and B as well as in triple-negative breast cancer subtypes (106). Furthermore, patients with HER2 overexpression had lower levels of S1P in comparison with those with HER2-negative breast cancer. Of note, the correlation between breast cancer tissue levels of S1P and ER or PR expression was not found in this study.

The presumption that increased S1P levels in breast cancer arise from the up-regulation of $S P H K 1$ holds true, as demonstrated by Tsuchida et al. (106) who confirmed the association by showing that breast cancer tissues with increased SPHK1 expression had markedly higher levels of S1P. Overexpression of SPHK1 seems to be an inherent feature of breast cancer as supported by several studies reporting that breast cancer tissues have higher expression levels of SPHK1 than patient-matched adjacent normal breast tissues which increased with advanced stages (108111). High SPHK1 expression significantly correlated with higher histological grading, lymphatic and distant metastasis, lower survival and poor prognosis in patients with breast cancer $(108,109)$.

The expression of SPHK1 was reported to vary between different molecular subtypes of breast cancer, which points to an intricate pattern of cross-regulation between sphingolipid metabolism and hormone- and growth factormediated signalling in breast cancer. For example, ERnegative tumours were found to have higher SPHK1 expression than ER-positive tumours, and its high tumour expression correlated with worse outcome regardless of the ER status (109, 112-114). Similarly, higher expression of SPHK1 was also detected in HER2-negative tumours than in HER2-positive tumours (111), and tumours with HER2 overexpression/amplification exhibited supressed expression of SPHK 1 (106). Interestingly, high tumour expression of SPHK1 was shown to be markedly associated with shorter survival of patients with HER2-positive breast cancer in comparison to those with HER2-positive tumours having low tumour expression of SPHK1 (112), although the clinical prognostic relevance of this finding should be additionally investigated in larger patient cohort. Confounding data were reported on the regulation of SPHK1 expression in triple-negative breast cancer. Some authors found that triple-negative tumours had a higher expression of SPHK1 mRNA in comparison with other breast tumours, which correlated with poor patient survival (109, 111). On the contrary, another study based on immunohistochemical analysis showed that triple-negative breast tumour tissues had lower tumour expression of phospho-SPHK 1 compared to tumours from luminal-type breast cancer (106). Discrepancy between the results obtained in these studies might be attributed to differences in methodology used to examine SPHK1 expression producing different types of molecular information, which hampers their comparison. Another reason may be a poor correlation between mRNA and protein abundances in cells as established in previous studies (115).

There is accumulating evidence that the expression levels of SPHK1 and S1PRs in combination with the ER status might be novel predictive indicators of therapy response and survival in breast cancer patients. In patients with ERpositive breast cancer who underwent tamoxifen treatment, it was shown that high membrane and cytoplasmic S1PR1 expression in tumours was significantly associated with shorter time to recurrence on tamoxifen (116). Similarly, high cytoplasmic S1PR3 expression levels correlated with reduced survival in these patients. Importantly, high nuclear and cytoplasmic expression levels of SPHK1 in tumours were shown to be significantly correlated with increased resistance to tamoxifen and poor survival in those with ERpositive breast cancer in comparison with patients with low tumour SPHK1 levels $(116,117)$. Opposing findings were obtained by Ruckhäberle et al., who found that patients with luminal ER-positive breast cancer with high tumour SPHK1 expression had a significantly higher pathological complete response rate after neoadjuvant treatment based on tamoxifen and doxorubicin in combination with either docetaxel or cyclophosphamide than those with low SPHK1 expression. (112) . Improved clinical outcome in this study in spite of high SPHK1 expression might, at least partially, be attributed to synergistic effects of the administered drug combinations.

Ceramide plays an important role in breast cancer pathogenesis as its levels were shown to be significantly increased in malignant breast cancer tissues compared to normal breast tissues $(104,118)$. In particular, a significant increase in the levels of C16:0, C18:0, C20:0, C22:0, C24:1, C24:0 and C26:1 ceramides was detected in breast cancer tissues relative to normal tissues $(104,119)$. This can be ascribed to increased mRNA levels of specific CERS including CERS2, CERS4 and CERS6 in breast cancer tissues in comparison with paired normal tissues $(118,119)$. Among the identified ceramide species, C16:0 ceramide stands out as the most promising prognostic biomarker since a significant increase in its levels was detected in tumour tissues from patients with a positive lymph node status relative to tumours with a negative lymph node status (118). The same authors 
also found that ER regulated the levels of specific ceramide species including $\mathrm{C} 18: 0$ and $\mathrm{C} 20: 0$ ceramides, as only these ceramides were markedly increased in ER-positive malignant breast cancer tissues in comparison with ER-negative tissues. Specific regulation of ceramide metabolism depending on the ER status was also demonstrated by several other studies. For example, increased expression of CERS4 and CERS6 was found in ER-positive tumours. In addition, ASAH1 expression was also shown to be higher in ER-positive than ER-negative tumours and correlate with improved prognosis of patients with ER-positive tumours (113). Prognostic significance of ASAH1 in breast cancer was also ascertained by Sänger et al., who reported that high expression of ASAH1 was associated with better prognosis in invasive breast cancer independently of the type of adjuvant treatment, and might be also considered a predictor for improved outcome in non-invasive ductal carcinoma in situ (29). The finding that ER-positive breast cancer has pronounced induction of ceramide synthesis and breakdown also points to a complex interplay between sphingolipid metabolic enzymes in the regulation of cancer cell behaviour. In support of this hypothesis, a recent study in colon cancer cells showed that increased expression of CERS6 transcriptionally activated ASAH1, resulting in increased mRNA, protein expression and activity of this enzyme (120).

\section{Conclusion and Perspective}

Identification of reliable and sensitive biomarkers for patient stratification remains a cornerstone for early cancer detection, prevention and achievement of the optimal treatment outcome. In spite of the rapid development of systems and integrative biology, the role of sphingolipids as cancer biomarkers has often been overlooked. Fortunately, this trend is about to change, as demonstrated by an increasing number of studies conducted in clinical settings which clearly showed diagnostic, prognostic and predictive potentials of simple sphingolipid species and the enzymes responsible for their synthesis and turnover in the management of patients with cancer. Discovery of novel sphingolipid-related biomarkers has been greatly facilitated by the advent of mass spectrometry-based sphingolipidomics that enables the analysis of large numbers of lipid species with a high degree of structural accuracy and sensitivity. Mass spectrometric analysis of human blood sphingolipids holds promise in delivering novel, non-invasive diagnostic biomarkers for cancer. However, it would be necessary first to determine reference (normal) concentration intervals and identify traits that induce normal perturbations in sphingolipid levels, such as age, sex, and ethnicity. Study on a large group of European population samples identified genetic variants that strongIy influence the circulating sphingolipid concentrations in the general population, which provides a rationale for further testing variants in these loci for their role in the development of cancer (121).

Clinical translation of sphingolipid biomarkers relies on studies in patients with cancer that often suffer from inconsistency. One of the reasons for this discrepancy between different studies performed on the same cancer type lies in tumour heterogeneity, histological type and anatomical sites of the tumour studied. In addition, the use of different analytical methods for the analysis of enzymes and receptors associated with sphingolipid metabolism and signalling (e.g. immunohistochemistry and real-time polymerase chain reaction) limits direct comparison of data obtained across multiple studies. Another issue that should not be overlooked is that many studies included rather small numbers of tumour samples, which does not fully represent the complexity of the underlying biology. Multi-centric studies in large and well-defined clinical cohorts, availability of good quality clinical samples, multi-region sampling of primary and metastatic tumours, and standardized analytical protocols for the measurement of sphingolipids and their metabolic enzymes could provide more uniform and reproducible data to facilitate translation from sphingolipid biomarker discovery to clinical utility.

A better understanding of the molecular mechanisms that regulate the enzymes of sphingolipid metabolism and their products in cancer, mapping of sphingolipid-protein interactions and deciphering biological roles of distinct sphingolipid species in cancer biology still remain challenging. Knowing that sphingolipid metabolism is intertwined with signalling networks that control cancer cell behaviour and fate, the use of sphingolipid-related biomarkers should be combined with the key molecular features characteristic for each cancer type (e.g. the expression of specific growth factor receptor, oncogene expression and mutational status, and hormone receptor status) in order to improve prognostic accuracy and specificity. In addition, the integration of validated sphingolipid biomarkers with current screening modalities would further increase diagnostic performance and help identify the best therapeutic approaches in patients with cancer.

\section{Funding}

This work was supported by the University of Rijeka under Grant number 13.11.2.1.12. to Mirela Sedic and 13.11.1.1.11 to Sandra Kraljević Pavelić.

\section{Disclosure Statement}

The Authors declare no conflict of interest in regard to this article.

\section{Ethics Approval}

This article does not contain any studies with human participants or animals performed by any of the Authors. 


\section{References}

1 Futerman $\mathrm{AH}$ and Riezman $\mathrm{H}$ : The ins and outs of sphingolipid synthesis. Trends Cell Biol 15: 312-318, 2005.

2 Gault CR, Obeid LM and Hannun YA: An overview of sphingolipid metabolism: from synthesis to breakdown. Adv Exp Med Biol 688: 1-23, 2010.

3 Merrill AH: Sphingolipid and glycosphingolipid metabolic pathways in the era of sphingolipidomics. Chem Rev 111: 63876422, 2011.

4 Brice SE and Cowart LA: Sphingolipid metabolism and analysis in metabolic disease. Adv Exp Med Biol 721: 1-17, 2011.

5 Chen Y, Liu Y, Sullards MC and Merrill AH: An introduction to sphingolipid metabolism and analysis by new technologies. Neuromol Med 12: 306-319, 2010.

6 Bao Y, Guo Y, Zhang C, Fan F and Yang W: Sphingosine kinase 1 and sphingosine-1-phosphate signaling in colorectal cancer. Int J Mol Sci 18: pii: E2109, 2017.

7 Zhu L, Wang Z, Lin Y, Chen Z, Liu H, Chen Y, Wang N and Song $\mathrm{X}$ : Sphingosine kinase 1 enhances the invasion and migration of non-small cell lung cancer cells via the AKT pathway. Oncol Rep 33: 1257-1263, 2015.

8 Zhang H, Wang Q, Zhao Q and Di W: $m i R-124$ inhibits the migration and invasion of ovarian cancer cells by targeting SPHK1. J Ovarian Res 6: 84, 2013.

9 Powell JA, Lewis AC, Zhu W, Toubia J, Pitman MR, Wallington-Beddoe CT, Moretti PAB, Iarossi D, Samaraweera SE, Cummings N, Ramshaw HS, Thomas D, Wei AH, Lopez AF, D'Andrea RJ, Lewis ID and Pitson SM: Targeting sphingosine kinase 1 induces MCL1-dependent cell death in acute myeloid leukemia. Blood 129: 771-782, 2017.

10 Dayon A, Brizuela L, Martin C, Mazerolles C, Pirot N, Doumerc N, Nogueira L, Golzio M, Teissié J, Serre G, Rischmann P, Malavaud B and Cuvillier O: Sphingosine kinase1 is central to androgen-regulated prostate cancer growth and survival. PLoS ONE 4(11): e8048, 2009.

11 Ruckhäberle E, Rody A, Engels K, Gaetje R, von Minckwitz G, Schiffmann S, Grösch S, Geisslinger G, Holtrich U, Karn T and Kaufmann M: Microarray analysis of altered sphingolipid metabolism reveals prognostic significance of sphingosine kinase 1 in breast cancer. Breast Cancer Res Treat 112: 41-52, 2008.

12 Van Brocklyn JR, Jackson CA, Pearl DK, Kotur MS, Snyder PJ and Prior TW: Sphingosine kinase-1 expression correlates with poor survival of patients with glioblastoma multiforme: roles of sphingosine kinase isoforms in growth of glioblastoma cell lines. J Neuropathol Exp Neurol 64: 695-705, 2005.

13 Nakajima M, Nagahashi M, Rashid OM, Takabe K and Wakai $\mathrm{T}$ : The role of sphingosine-1-phosphate in the tumor microenvironment and its clinical implications. Tumour Biol 39: 1010428317699133, 2017.

14 Albinet V, Bats M-L, Huwiler A, Rochaix P, Chevreau C, Ségui $\mathrm{B}$, Levade T and Andrieu-Abadie N: Dual role of sphingosine kinase- 1 in promoting the differentiation of dermal fibroblasts and the dissemination of melanoma cells. Oncogene 33: 33643373, 2014.

15 Liu W, Ning J, Li C, Hu J, Meng Q, Lu H and Cai L: Overexpression of SPHK2 is associated with gefitinib resistance in non-small cell lung cancer. Tumour Biol 37: 6331-6336, 2016.
16 Xun C, Chen M-B, Qi L, Tie-Ning Z, Peng X, Ning L, ZhiXiao $\mathrm{C}$ and Li-Wei W: Targeting sphingosine kinase 2 (SphK2) by $\mathrm{ABC} 294640$ inhibits colorectal cancer cell growth in vitro and in vivo. J Exp Clin Cancer Res 34: 94, 2015.

17 Sun E, Zhang W, Wang L, Wang A, Ma C, Lei M, Zhou X, Sun Y, Lu B, Liu L and Han R: Down-regulation of SPHK2 suppresses bladder cancer progression. Tumour Biol 37: 473$478,2016$.

18 Venant H, Rahmaniyan M, Jones EE, Lu P, Lilly MB, GarrettMayer E, Drake RR, Kraveka JM, Smith CD and VoelkelJohnson C: The sphingosine kinase 2 inhibitor ABC294640 reduces the growth of prostate cancer cells and results in accumulation of dihydroceramides in vitro and in vivo. Mol Cancer Ther 14: 2744-2752, 2015.

19 White MD, Chan L, Antoon JW and Beckman BS: Targeting ovarian cancer and chemoresistance through selective inhibition of sphingosine kinase-2 with ABC294640. Anticancer Res 33: 3573-3579, 2013.

20 Beljanski V, Lewis CS and Smith CD: Antitumor activity of sphingosine kinase 2 inhibitor ABC294640 and sorafenib in hepatocellular carcinoma xenografts. Cancer Biol Ther 11: 524534, 2011.

21 Gao P and Smith CD: Ablation of sphingosine kinase-2 inhibits tumor cell proliferation and migration. Mol Cancer Res MCR 9: 1509-1519, 2011.

22 Neubauer HA, Pham DH, Zebol JR, Moretti PAB, Peterson AL, Leclercq TM, Chan H, Powell JA, Pitman MR, Samuel MS, Bonder CS, Creek DJ, Gliddon BL and Pitson SM: An oncogenic role for sphingosine kinase 2. Oncotarget 7: 6488664899, 2016.

23 Saddoughi SA and Ogretmen B: Diverse functions of ceramide in cancer cell death and proliferation. Adv Cancer Res 117: 3758, 2013.

24 Hartmann D, Lucks J, Fuchs S, Schiffmann S, Schreiber Y, Ferreirós N, Merkens J, Marschalek R, Geisslinger G and Grösch S: Long chain ceramides and very long-chain ceramides have opposite effects on human breast and colon cancer cell growth. Int J Biochem Cell Biol 44: 620-628, 2012.

25 Hartmann D, Wegner M-S, Wanger RA, Ferreirós N, Schreiber Y, Lucks J, Schiffmann S, Geisslinger $G$ and Grösch S: The equilibrium between long- and very long-chain ceramides is important for the fate of the cell and can be influenced by coexpression of CerS. Int J Biochem Cell Biol 45: 1195-1203, 2013.

26 Liu X, Cheng JC, Turner LS, Elojeimy S, Beckham TH, Bielawska A, Keane TE, Hannun YA and Norris JS: Acid ceramidase up-regulation in prostate cancer: Role in tumour development and implications for therapy. Expert Opin Ther Targets 13: 1449-1458, 2009.

27 Morales A, París R, Villanueva A, Llacuna L, García-Ruiz C and Fernández-Checa JC: Pharmacological inhibition or small interfering RNA targeting acid ceramidase sensitizes hepatoma cells to chemotherapy and reduces tumor growth in vivo. Oncogene 26: 905-916, 2007.

28 Roh J-L, Park JY, Kim EH and Jang HJ: Targeting acid ceramidase sensitises head and neck cancer to cisplatin. Eur J Cancer 52: 163-172, 2016.

29 Sänger N, Ruckhäberle E, Györffy B, Engels K, Heinrich T, Fehm T, Graf A, Holtrich U, Becker S and Karn T: Acid ceramidase is associated with an improved prognosis in both DCIS and invasive breast cancer. Mol Oncol 9: 58-67, 2015. 
30 Realini N, Solorzano C, Pagliuca C, Pizzirani D, Armirotti A, Luciani R, Costi MP, Bandiera T and Piomelli D: Discovery of highly potent acid ceramidase inhibitors with in vitro tumor chemosensitizing activity. Sci Rep 3: 1035, 2013.

31 Lai M, Realini N, Ferla M, Passalacqua I, Matteoli G, Ganesan A, Pistello M, Mazzanti CM and Piomelli D: Complete acid ceramidase ablation prevents cancer-initiating cell formation in melanoma cells. Sci Rep 7: 7411, 2017.

$32 \mathrm{Hu} \mathrm{X}$, Yang D, Zimmerman M, Liu F, Yang J, Kannan S, Burchert A, Szulc Z, Bielawska A, Ozato K, Bhalla K and Liu $\mathrm{K}$ : IRF8 regulates acid ceramidase expression to mediate apoptosis and suppresses myelogeneous leukaemia. Cancer Res 71: 2882-2891, 2011.

33 Liu S-Q, Su Y-J, Qin M-B, Mao Y-B, Huang J-A and Tang G$\mathrm{D}$ : Sphingosine kinase 1 promotes tumor progression and confers malignancy phenotypes of colon cancer by regulating the focal adhesion kinase pathway and adhesion molecules. Int J Oncol 42: 617-626, 2013.

34 Roh J-L, Kim EH, Park JY and Kim JW: Inhibition of glucosylceramide synthase sensitizes head and neck cancer to cisplatin. Mol Cancer Ther 14: 1907-1915, 2015.

35 Tyler A, Johansson A, Karlsson T, Gudey SK, Brännström T, Grankvist $\mathrm{K}$ and Behnam-Motlagh P: Targeting glucosylceramide synthase induction of cell surface globotriaosylceramide (GB3) in acquired cisplatin-resistance of lung cancer and malignant pleural mesothelioma cells. Exp Cell Res 336: 23-32, 2015.

36 Wang T, Wei J, Wang N, Ma J-L and Hui P-P: The glucosylceramide synthase inhibitor PDMP sensitizes pancreatic cancer cells to MEK/ERK inhibitor AZD-6244. Biochem Biophys Res Commun 456: 821-826, 2015.

37 Stefanovic M, Tutusaus A, Martinez-Nieto GA, Bárcena C, de Gregorio E, Moutinho C, Barbero-Camps E, Villanueva A, Colell A, Marí M, García-Ruiz C, Fernandez-Checa JC and Morales A: Targeting glucosylceramide synthase upregulation reverts sorafenib resistance in experimental hepatocellular carcinoma. Oncotarget 7: 8253-8267, 2016.

38 Nunes J, Naymark M, Sauer L, Muhammad A, Keun H, Sturge $\mathrm{J}$, Stebbing $\mathrm{J}$, Waxman $\mathrm{J}$ and Pchejetski D: Circulating sphingosine-1-phosphate and erythrocyte sphingosine kinase-1 activity as novel biomarkers for early prostate cancer detection. Br J Cancer 106: 909-915, 2012.

39 Malavaud B, Pchejetski D, Mazerolles C, de Paiva GR, Calvet C, Doumerc N, Pitson S, Rischmann P and Cuvillier O: Sphingosine kinase-1 activity and expression in human prostate cancer resection specimens. Eur J Cancer 1990 46: 3417-3424, 2010.

40 Seelan RS, Qian C, Yokomizo A, Bostwick DG, Smith DI and Liu W: Human acid ceramidase is overexpressed but not mutated in prostate cancer. Genes Chromosomes Cancer 29: 137-146, 2000

41 Norris JS, Bielawska A, Day T, El-Zawahri A, ElOjeimy S, Hannun Y, Holman D, Hyer M, Landon C, Lowe S, Dong JY, McKillop J, Norris K, Obeid L, Rubinchik S, Tavassoli M, Tomlinson S, Voelkel-Johnson $\mathrm{C}$ and Liu X: Combined therapeutic use of AdGFPFasL and small molecule inhibitors of ceramide metabolism in prostate and head and neck cancers: A status report. Cancer Gene Ther 13: 1045-1051, 2006.

42 Camacho L, Meca-Cortés O, Abad JL, García S, Rubio N, Díaz A, Celià-Terrassa T, Cingolani F, Bermudo R, Fernández PL, Blanco J, Delgado A, Casas J, Fabriàs G and Thomson TM: Acid ceramidase as a therapeutic target in metastatic prostate cancer. J Lipid Res 54: 1207-1220, 2013.
43 Cheng JC, Bai A, Beckham TH, Marrison ST, Yount CL, Young $\mathrm{K}, \mathrm{Lu}$ P, Bartlett AM, Wu BX, Keane BJ, Armeson KE, Marshall DT, Keane TE, Smith MT, Jones EE, Drake RR, Bielawska A, Norris JS and Liu X: Radiation-induced acid ceramidase confers prostate cancer resistance and tumor relapse. J Clin Invest 123: 4344-4358, 2013.

44 Waller LP, Deshpande V and Pyrsopoulos N: Hepatocellular carcinoma: A comprehensive review. World J Hepatol 7: 26482663,2015

45 Cai H, Xie X, Ji L, Ruan X and Zheng Z: Sphingosine kinase 1: A novel independent prognosis biomarker in hepatocellular carcinoma. Oncol Lett 13: 2316-2322, 2017

46 Uranbileg B, Ikeda H, Kurano M, Enooku K, Sato M, Saigusa D, Aoki J, Ishizawa T, Hasegawa K, Kokudo N and Yatomi Y: Increased mRNA levels of sphingosine kinases and S1P lyase and reduced levels of S1P were observed in hepatocellular carcinoma in association with poorer differentiation and earlier recurrence. PloS One 11: e0149462, 2016

47 Grammatikos G, Schoell N, Ferreirós N, Bon D, Herrmann E, Farnik H, Köberle V, Piiper A, Zeuzem S, Kronenberger B, Waidmann $\mathrm{O}$ and Pfeilschifter J: Serum sphingolipidomic analyses reveal an up-regulation of C16-ceramide and sphingosine-1-phosphate in hepatocellular carcinoma. Oncotarget 7: 18095-18105, 2016.

48 Ressom HW, Xiao JF, Tuli L, Varghese RS, Zhou B, Tsai T-H, Ranjbar MRN, Zhao Y, Wang J, Di Poto C, Cheema AK, Tadesse MG, Goldman R and Shetty K: Utilization of metabolomics to identify serum biomarkers for hepatocellular carcinoma in patients with liver cirrhosis. Anal Chim Acta 743: 90-100, 2012.

49 Fitian AI, Nelson DR, Liu C, Xu Y, Ararat M and Cabrera R: Integrated metabolomic profiling of hepatocellular carcinoma in hepatitis $\mathrm{C}$ cirrhosis through GC/MS and UPLC/MS-MS. Liver Int 34: 1428-1444, 2014.

50 Krautbauer S, Meier EM, Rein-Fischboeck L, Pohl R, Weiss TS, Sigruener A, Aslanidis C, Liebisch G and Buechler C: Ceramide and polyunsaturated phospholipids are strongly reduced in human hepatocellular carcinoma. Biochim Biophys Acta 1861: 1767-1774, 2016.

51 Krautbauer S, Weiss TS, Wiest R, Schacherer D, Liebisch G and Buechler C: Diagnostic value of systemic cholesteryl ester/free cholesterol ratio in hepatocellular carcinoma. Anticancer Res 37: 3527-3535, 2017.

52 Tholey R, Sawicki JA and Brody JR: Molecular-based and alternative therapies for pancreatic cancer: looking "out of the box." Cancer J 18: 665-673, 2012.

53 Ballehaninna UK and Chamberlain RS: Serum CA 19-9 as a biomarker for pancreatic cancer - A comprehensive review. Indian J Surg Oncol 2: 88-100, 2011.

54 Jiang Y, DiVittore NA, Young MM, Jia Z, Xie K, Ritty TM, Kester $M$ and Fox TE: Altered sphingolipid metabolism in patients with metastatic pancreatic cancer. Biomolecules 3: 435448, 2013.

55 Di Gangi IM, Mazza T, Fontana A, Copetti M, Fusilli C, Ippolito A, Mattivi F, Latiano A, Andriulli A, Vrhovsek U and Pazienza V: Metabolomic profile in pancreatic cancer patients: a consensus-based approach to identify highly discriminating metabolites. Oncotarget 7: 5815-5829, 2016

56 Arnold M, Sierra MS, Laversanne M, Soerjomataram I, Jemal A and Bray F: Global patterns and trends in colorectal cancer incidence and mortality. Gut 66: 683-691, 2017. 
57 Fung KYC, Tabor B, Buckley MJ, Priebe IK, Purins L, Pompeia C, Brierley GV, Lockett T, Gibbs P, Tie J, McMurrick P, Moore J, Ruszkiewicz A, Nice E, Adams TE, Burgess A and Cosgrove LJ: Blood-based protein biomarker panel for the detection of colorectal cancer. PLoS ONE 10(3): e0120425, 2015.

58 Junjun $\mathrm{Y}$, Yao H, Yuanyuan $\mathrm{Z}$, Xiaoning $\mathrm{Z}$ and Xiqiao Z: Expression of sphingosine-1-phosphate receptor2 in human colon cancer and its correlation with cancer migration and invasion. Gastroenterology 152: S1024, 2017.

59 Kawamori T, Kaneshiro T, Okumura M, Maalouf S, Uflacker A, Bielawski J, Hannun YA and Obeid LM: Role for sphingosine kinase 1 in colon carcinogenesis. FASEB J 23: 405-414, 2009.

60 Samuhasaneeto S, Promagsorn S and Punsawad C: Sphingosine 1-phosphate receptor 4 expression in colorectal cancer patients. Walailak J Sci Technol 14: 663-669, 2016.

61 Long J, Xie Y, Yin J, Lu W and Fang S: SPHK1 promotes tumor cell migration and invasion in colorectal cancer. Tumour Biol 37: 6831-6836, 2016.

62 Tan SSL, Khin LW, Wong L, Yan B, Ong CW, Datta A, SaltoTellez M, Lam Y and Yap CT: Sphingosine kinase 1 promotes malignant progression in colon cancer and independently predicts survival of patients with colon cancer by competing risk approach in South Asian population. Clin Transl Gastroenterol 5: e51, 2014.

63 Rosa R, Marciano R, Malapelle U, Formisano L, Nappi L, D'Amato C, D'Amato V, Damiano V, Marfè G, Del Vecchio S, Zannetti A, Greco A, De Stefano A, Carlomagno C, Veneziani BM, Troncone G, De Placido S and Bianco R: Sphingosine kinase 1 overexpression contributes to cetuximab resistance in human colorectal cancer models. Clin Cancer Res 19: 138-147, 2013.

64 Lin Q, Wei Y, Zhong Y, Zhu D, Ren L, Xu P, Zheng P, Feng Q, Ji M, Lv M, Liang $\mathrm{C}$ and $\mathrm{Xu} \mathrm{J}$ : Aberrant expression of sphingosine-1-phosphate receptor 1 correlates with metachronous liver metastasis and poor prognosis in colorectal cancer. Tumour Biol 35: 9743-9750, 2014.

65 Separovic D, Shields AF, Philip PA, Bielawski J, Bielawska A, Pierce JS and Tarca AL: Altered levels of serum ceramide, sphingosine and sphingomyelin are associated with colorectal cancer: A retrospective pilot study. Anticancer Res 37: 12131218, 2017.

66 Chen L, Chen H, Li Y, Li L, Qiu Y and Ren J: Endocannabinoid and ceramide levels are altered in patients with colorectal cancer. Oncol Rep 34: 447-454, 2015.

67 Hanash SM, Pitteri SJ and Faca VM: Mining the plasma proteome for cancer biomarkers. Nature 452: 571-579, 2008.

68 Kijanka G, Hector S, Kay EW, Murray F, Cummins R, Murphy D, MacCraith BD, Prehn JHM and Kenny D: Human IgG antibody profiles differentiate between symptomatic patients with and without colorectal cancer. Gut 59: 69-78, 2010.

69 Fitzgerald S, Sheehan KM, Espina V, O'Grady A, Cummins R, Kenny D, Liotta L, O'Kennedy R, Kay EW and Kijanka GS: High CerS5 expression levels associate with reduced patient survival and transition from apoptotic to autophagy signalling pathways in colorectal cancer. J Pathol Clin Res 1: 54-65, 2014.

70 Dubois N, Rio E, Ripoche N, Ferchaud-Roucher V, Gaugler MH, Campion L, Krempf M, Carrie C, Mahé M, Mirabel X and Paris F: Plasma ceramide, a real-time predictive marker of pulmonary and hepatic metastases response to stereotactic body radiation therapy combined with irinotecan. Radiother Oncol J Eur Soc Ther Radiol Oncol 119: 229-235, 2016.
71 Pollock NI and Grandis JR: HER2 as a Therapeutic Target in Head and Neck Squamous Cell Carcinoma. Clin Cancer Res 21: 526-533, 2015.

72 Birkeland AC and Brenner JC: Personalizing medicine in head and neck squamous cell carcinoma: The rationale for combination therapies. Med Res Arch 3, 2015. doi: 10.18103/mra.v0i3.77.

73 Yuan Y, Chi F, Wang S and Wang Z: Significance of ceramide and DNA ploidy in laryngeal carcinogenesis. ORL 69: 283-288, 2007.

74 Chi F-L, Yuan Y-S, Wang S-Y and Wang Z-M: Study on ceramide expression and DNA content in patients with healthy mucosa, leukoplakia, and carcinoma of the larynx. Arch Otolaryngol Head Neck Surg 130: 307-310, 2004.

75 Young MRI, Neville BW, Chi AC, Lathers DMR, Gillespie MB and Day TA: Autocrine motility-stimulatory pathways of oral premalignant lesion cells. Clin Exp Metastasis 24: 131-139, 2007.

76 Elojeimy S, Liu X, McKillop JC, El-Zawahry AM, Holman DH, Cheng JY, Meacham WD, Mahdy AE, Saad AF, Turner LS, Cheng J, A Day T, Dong J-Y, Bielawska A, Hannun YA and Norris JS: Role of acid ceramidase in resistance to FasL: therapeutic approaches based on acid ceramidase inhibitors and FasL gene therapy. Mol Ther 15: 1259-1263, 2007.

77 Marques Filho MF, Walder F, Takahashi HK, Guimarães LL, Tanaka AK, Cervantes O and Straus AH: Glycosphingolipid expression in squamous cell carcinoma of the upper aerodigestive tract. Braz J Otorhinolaryngol 72: 25-30, 2006.

78 Koybasi S, Senkal CE, Sundararaj K, Spassieva S, Bielawski J, Osta W, Day TA, Jiang JC, Jazwinski SM, Hannun YA, Obeid LM and Ogretmen B: Defects in cell growth regulation by C18:0-ceramide and longevity assurance gene 1 in human head and neck squamous cell carcinomas. J Biol Chem 279: 4431144319, 2004.

79 Karahatay S, Thomas K, Koybasi S, Senkal CE, ElOjeimy S, Liu X, Bielawski J, Day TA, Boyd Gillespie M, Sinha D, Norris JS, Hannun YA and Ogretmen B: Clinical relevance of ceramide metabolism in the pathogenesis of human head and neck squamous cell carcinoma (HNSCC): Attenuation of C18ceramide in HNSCC tumors correlates with lymphovascular invasion and nodal metastasis. Cancer Lett 256: 101-111, 2007.

80 Saddoughi SA, Garrett-Mayer E, Chaudhary U, O'Brien PE, Afrin LB, Day TA, Gillespie MB, Sharma AK, Wilhoit CS, Bostick R, Senkal CE, Hannun YA, Bielawski J, Simon GR, Shirai K and Ogretmen B: Results of a phase II trial of gemcitabine plus doxorubicin in patients with recurrent head and neck cancers: serum C18-ceramide as a novel biomarker for monitoring response. Clin Cancer Res 17: 6097-6105, 2011.

81 Shirai K, Kaneshiro T, Wada M, Furuya H, Bielawski J, Hannun YA, Obeid LM, Ogretmen B and Kawamori T: A role of sphingosine kinase 1 in head and neck carcinogenesis. Cancer Prev Res 4: 454-462, 2011.

82 Facchinetti MM, Gandini NA, Fermento ME, Sterin-Speziale NB, Ji Y, Patel V, Gutkind JS, Rivadulla MG and Curino AC: The expression of sphingosine kinase-1 in head and neck carcinoma. Cells Tissues Organs 192: 314-324, 2010.

83 Li W, Tian Z, Qin H, Li N, Zhou X, Li J, Ni B and Ruan Z: High expression of sphingosine kinase 1 is associated with poor prognosis in nasopharyngeal carcinoma. Biochem Biophys Res Commun 460: 341-347, 2015. 
84 Vishwakarma S, Agarwal R, Goel SK, Panday RK, Singh R, Sukumaran R, Khare S and Kumar A: Altered expression of sphingosine-1-phosphate metabolizing enzymes in oral cancer correlate with clinicopathological attributes. Cancer Invest 35: 139-141, 2017.

85 Patmanathan SN, Johnson SP, Lai SL, Panja Bernam S, Lopes V, Wei W, Ibrahim MH, Torta F, Narayanaswamy P, Wenk MR, Herr DR, Murray PG, Yap LF and Paterson IC: Aberrant expression of the S1P regulating enzymes, SPHK1 and SGPL1, contributes to a migratory phenotype in OSCC mediated through S1PR2. Sci Rep 6: 25650, 2016.

86 Sinha UK, Schorn VJ, Hochstim C, Chinn SB, Zhu S and Masood R: Increased radiation sensitivity of head and neck squamous cell carcinoma with sphingosine kinase 1 inhibition. Head Neck 33: 178-188, 2011.

87 Huang B, Zhang H, Gu L, Ye B, Jian Z, Stary C and Xiong X: Advances in immunotherapy for glioblastoma multiforme. J Immunol Res 2017: 3597613, 2017

88 Abuhusain HJ, Matin A, Qiao Q, Shen H, Kain N, Day BW, Stringer BW, Daniels B, Laaksonen MA, Teo C, McDonald KL and Don AS: A metabolic shift favoring sphingosine 1phosphate at the expense of ceramide controls glioblastoma angiogenesis. J Biol Chem 288: 37355-37364, 2013.

89 Riboni L, Campanella R, Bassi R, Villani R, Gaini SM, Martinelli-Boneschi F, Viani P and Tettamanti G: Ceramide levels are inversely associated with malignant progression of human glial tumors. Glia 39: 105-113, 2002.

90 Doan NB, Nguyen HS, Montoure A, Al-Gizawiy MM, Mueller WM, Kurpad S, Rand SD, Connelly JM, Chitambar CR, Schmainda KM and Mirza SP: Acid ceramidase is a novel drug target for pediatric brain tumors. Oncotarget 8: 24753-24761, 2017.

91 Al-Gizawiy MM, Doan NB, Schmainda KM, Palomares JA, Mueller WM, Connelly JM and Mirza SP: MPTH-28. Acid ceramidase is a supplementary biomarker of survival in glioma. Neuro-Oncol 18: vi112-vi112, 2016.

92 Doan NB, Nguyen HS, Al-Gizawiy MM, Mueller WM, Sabbadini RA, Rand SD, Connelly JM, Chitambar CR, Schmainda KM and Mirza SP: Acid ceramidase confers radioresistance to glioblastoma cells. Oncol Rep 38: 1932-1940, 2017.

93 Jensen SA, Calvert AE, Volpert G, Kouri FM, Hurley LA, Luciano JP, Wu Y, Chalastanis A, Futerman AH and Stegh AH: BCL2L13 is a ceramide synthase inhibitor in glioblastoma. Proc Natl Acad Sci USA 111: 5682-5687, 2014.

94 Quint K, Stiel N, Neureiter D, Schlicker HU, Nimsky C, Ocker M, Strik H and Kolodziej MA: The role of sphingosine kinase isoforms and receptors S1P1, S1P2, S1P3, and S1P5 in primary, secondary, and recurrent glioblastomas. Tumour Biol 35: 89798989,2014

95 Li J, Guan H-Y, Gong L-Y, Song L-B, Zhang N, Wu J, Yuan J, Zheng Y-J, Huang Z-S and Li M: Clinical significance of sphingosine kinase-1 expression in human astrocytomas progression and overall patient survival. Clin Cancer Res 14: 6996-7003, 2008

96 Bien-Möller S, Lange S, Holm T, Böhm A, Paland H, Küpper J, Herzog S, Weitmann K, Havemann C, Vogelgesang S, Marx S, Hoffmann W, Schroeder HWS and Rauch BH: Expression of S1P metabolizing enzymes and receptors correlate with survival time and regulate cell migration in glioblastoma multiforme. Oncotarget 7: 13031-13046, 2016
97 Van Brocklyn JR, Young N and Roof R: Sphingosine-1phosphate stimulates motility and invasiveness of human glioblastoma multiforme cells. Cancer Lett 199: 53-60, 2003.

98 Van Brocklyn J, Letterle C, Snyder P and Prior T: Sphingosine1-phosphate stimulates human glioma cell proliferation through Gi-coupled receptors: Role of ERK MAP kinase and phosphatidylinositol 3-kinase beta. Cancer Lett 181: 195-204, 2002.

99 Yoshida Y, Nakada M, Sugimoto N, Harada T, Hayashi Y, Kita D, Uchiyama N, Hayashi Y, Yachie A, Takuwa Y and Hamada J-I: Sphingosine-1-phosphate receptor type 1 regulates glioma cell proliferation and correlates with patient survival. Int $\mathbf{J}$ Cancer 126: 2341-2352, 2010.

100 Yoshida Y, Nakada M, Harada T, Tanaka S, Furuta T, Hayashi Y, Kita D, Uchiyama N, Hayashi Y and Hamada J: The expression level of sphingosine-1-phosphate receptor type 1 is related to MIB-1 labeling index and predicts survival of glioblastoma patients. J Neurooncol 98: 41-47, 2010.

101 Vartanian A, Singh SK, Agnihotri S, Jalali S, Burrell K, Aldape KD and Zadeh G: GBM's multifaceted landscape: highlighting regional and microenvironmental heterogeneity. Neuro-Oncol 16: 1167-1175, 2014

102 Young N and Van Brocklyn JR: Roles of sphingosine-1phosphate $(\mathrm{S} 1 \mathrm{P})$ receptors in malignant behavior of glioma cells. Differential effects of S1P2 on cell migration and invasiveness. Exp Cell Res 313: 1615-1627, 2007.

103 Dai X, Li T, Bai Z, Yang Y, Liu X, Zhan J and Shi B: Breast cancer intrinsic subtype classification, clinical use and future trends. Am J Cancer Res 5: 2929-2943, 2015.

104 Nagahashi M, Tsuchida J, Moro K, Hasegawa M, Tatsuda K, Woelfel IA, Takabe K and Wakai T: High levels of sphingolipids in human breast cancer. J Surg Res 204: 435-444, 2016.

105 Nagahashi M, Yamada A, Miyazaki H, Allegood JC, Tsuchida J, Aoyagi T, Huang W-C, Terracina KP, Adams BJ, Rashid OM, Milstien S, Wakai T, Spiegel S and Takabe K: Interstitial fluid sphingosine-1-phosphate in murine mammary gland and cancer and human breast tissue and cancer determined by novel methods. J Mammary Gland Biol Neoplasia 21: 9-17, 2016.

106 Tsuchida J, Nagahashi M, Nakajima M, Moro K, Tatsuda K, Ramanathan $\mathrm{R}$, Takabe $\mathrm{K}$ and Wakai $\mathrm{T}$ : Breast cancer sphingosine-1-phosphate is associated with phosphosphingosine kinase 1 and lymphatic metastasis. J Surg Res 205: 85-94, 2016.

107 Nagahashi M, Ramachandran S, Kim EY, Allegood JC, Rashid OM, Yamada A, Zhao R, Milstien S, Zhou H, Spiegel S and Takabe K: Sphingosine-1-phosphate produced by sphingosine kinase 1 promotes breast cancer progression by stimulating angiogenesis and lymphangiogenesis. Cancer Res 72: 726-735, 2012.

108 Zhu Y-J, You H, Tan J-X, Li F, Qiu Z, Li H-Z, Huang H-Y, Zheng $\mathrm{K}$ and Ren G-S: Overexpression of sphingosine kinase 1 is predictive of poor prognosis in human breast cancer. Oncol Lett 14: 63-72, 2017.

109 Datta A, Loo SY, Huang B, Wong L, Tan SSL, Tan TZ, Lee SC, Thiery JP, Lim YC, Yong WP, Lam Y, Kumar AP and Yap CT: SPHK1 regulates proliferation and survival responses in triple-negative breast cancer. Oncotarget 5: 5920-5933, 2014.

110 Ling B, Chen L, Alcorn J, Ma B and Yang J: Sphingosine-1phosphate: a potential therapeutic agent against human breast cancer. Invest New Drugs 29: 396-399, 2011. 
111 Wang S, Liang Y, Chang W, Hu B and Zhang Y: Triple-negative breast cancer depends on sphingosine kinase 1 (SphK1)/ sphingosine-1-phosphate (S1P)/sphingosine 1-phosphate receptor 3 (S1PR3)/NOTCH signaling for metastasis. Med Sci Monit 24: 1912-1923, 2018.

112 Ruckhäberle E, Karn T, Denkert C, Loibl S, Ataseven B, Reimer T, Becker S, Holtrich U, Rody A, Darb-Esfahani S, Nekljudova V and von Minckwitz G: Predictive value of sphingosine kinase 1 expression in neoadjuvant treatment of breast cancer. J Cancer Res Clin Oncol 139: 1681-1689, 2013.

113 Ruckhäberle E, Holtrich U, Engels K, Hanker L, Gätje R, Metzler D, Karn T, Kaufmann M and Rody A: Acid ceramidase 1 expression correlates with a better prognosis in ER-positive breast cancer. Climacteric J Int Menopause Soc 12: 502-513, 2009.

114 Nazouri A-S, Asadpour O, Dabiri S, Pourseyedi B, Lashkarizadeh MR and Zianalinejad $\mathrm{H}$ : High expression of sphingosine kinase 1 in estrogen and progesterone receptorsnegative breast cancer. Iran J Pathol 12: 218-224, 2017.

115 Maier T, Güell M and Serrano L: Correlation of mRNA and protein in complex biological samples. FEBS Lett 583: 39663973, 2009.

116 Watson C, Long JS, Orange C, Tannahill CL, Mallon E, McGlynn LM, Pyne S, Pyne NJ and Edwards J: High expression of sphingosine 1-phosphate receptors, S1P1 and $\mathrm{S} 1 \mathrm{P} 3$, sphingosine kinase 1, and extracellular signal-regulated kinase-1/2 is associated with development of tamoxifen resistance in estrogen receptor-positive breast cancer patients. Am J Pathol 177: 2205-2215, 2010.

117 Long JS, Edwards J, Watson C, Tovey S, Mair KM, Schiff R, Natarajan V, Pyne NJ and Pyne S: Sphingosine kinase 1 induces tolerance to human epidermal growth factor receptor 2 and prevents formation of a migratory phenotype in response to sphingosine 1-phosphate in estrogen receptor-positive breast cancer cells. Mol Cell Biol 30: 3827-3841, 2010.
118 Schiffmann S, Sandner J, Birod K, Wobst I, Angioni C, Ruckhäberle E, Kaufmann M, Ackermann H, Lötsch J, Schmidt $\mathrm{H}$, Geisslinger $\mathrm{G}$ and Grösch S: Ceramide synthases and ceramide levels are increased in breast cancer tissue. Carcinogenesis 30: 745-752, 2009.

119 Erez-Roman R, Pienik R and Futerman AH: Increased ceramide synthase 2 and 6 mRNA levels in breast cancer tissues and correlation with sphingosine kinase expression. Biochem Biophys Res Commun 391: 219-223, 2010.

120 Tirodkar TS, Lu P, Bai A, Scheffel MJ, Gencer S, GarrettMayer E, Bielawska A, Ogretmen B and Voelkel-Johnson C: Expression of ceramide synthase 6 transcriptionally activates acid ceramidase in a c-Jun $\mathrm{N}$-terminal kinase (JNK)-dependent manner. J Biol Chem 290: 13157-13167, 2015.

121 Hicks AA, Pramstaller PP, Johansson Å, Vitart V, Rudan I, Ugocsai P, Aulchenko Y, Franklin CS, Liebisch G, Erdmann J, Jonasson I, Zorkoltseva IV, Pattaro C, Hayward C, Isaacs A, Hengstenberg C, Campbell S, Gnewuch C, Janssens ACW, Kirichenko AV, König IR, Marroni F, Polasek O, Demirkan A, Kolcic I, Schwienbacher C, Igl W, Biloglav Z, Witteman JCM, Pichler I, Zaboli G, Axenovich TI, Peters A, Schreiber S, Wichmann H-E, Schunkert H, Hastie N, Oostra BA, Wild SH, Meitinger T, Gyllensten U, Duijn CM van, Wilson JF, Wright A, Schmitz G and Campbell H: Genetic determinants of circulating sphingolipid concentrations in european populations. PLOS Genet 5: e1000672, 2009.
Received October 29, 2018

Revised November 19, 2018

Accepted November 21, 2018 